\title{
Rapid and nondestructive detection of watercore and sugar content in Asian pear by near infrared spectroscopy for commercial trade
}

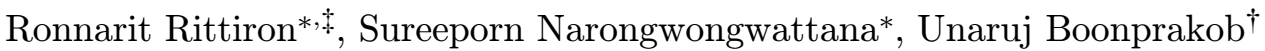 \\ and Worapa Seehalak* \\ *Department of Food Engineering, Faculty of Engineering at Kamphaengsaen \\ Kasetsart University, Nakhonpathom, Thailand \\ ${ }^{\dagger}$ Department of Horticulture, Faculty of Agriculture at Kamphaengsaen \\ Kasetsart University, Nakhonpathom, Thailand \\ †engror@ku.ac.th
}

Received 1 August 2013

Accepted 20 October 2013

Published 28 November 2013

\begin{abstract}
Watercore and sugar content are internal qualities which are impossible for exterior determination. Therefore the aims of this study were to develop models for nondestructive detection of watercore and predicting sugar content in pear using Near Infrared Spectroscopy (NIR) technique. A total of 93 samples of Asian pear variety "SH-078" were used. For sugar content, spectrum of each fruit was measured in the short wavelength region $(700-1100 \mathrm{~nm})$ in the reflection mode and the first derivative of spectra were then correlated with the sugar content in juice determined by digital refractometer. Prediction equation was performed by multiple linear regression. The result showed Standard Error of Prediction $(\mathrm{SEP})=0.58^{\circ} \mathrm{Bx}$, and Bias $=0.11$. The result from $t$-test showed that sugar content predicted by NIR was not significantly different from the value analyzed by refractometer at $95 \%$ confidence. For watercore disorder, NIR measurement was performed over the short wavelength range $(700-850 \mathrm{~nm})$ in the transmission mode. The first derivative spectra were correlated with internal qualities. Then principle component analysis (PCA) and partial least squares discriminant analysis (PLSDA) were used to perform discrimination models. The accuracy of the PCA model was greater than the PLSDA one. The scores from PC1 were separated into two boundaries, one predicted rejected pears with $100 \%$ classification accuracy, and the other was accepted pears with $92 \%$ accuracy. The high accuracy of sugar content determining and watercore detecting by NIR reveal the high efficiency of NIR technique for detecting other internal qualities of fruit in the future.
\end{abstract}

Keywords: NIR; internal quality; damage; calibration model.

This is an Open Access article published by World Scientific Publishing Company. It is distributed under the terms of the Creative Commons Attribution 3.0 (CC-BY) License. Further distribution of this work is permitted, provided the original work is properly cited. 


\section{Introduction}

Pear is one of fruits under the research and extension of the Royal Project Foundation (RPF). They are mostly cultivated in Chiang Mai and Chiang Rai provinces and produce per year $2200-3000 \mathrm{~kg} .{ }^{1}$ Thai consumers like to consume fresh fruit, but some fruits are not sweet enough and some get watercore damage. These are internal qualities which are difficult to investigate without cutting fruit. Sugar content can be used for grading. Fruits with higher sugar content will be sold in higher price. Presenting sugar content on each fruit will be a great way for the seller to guarantee sweetness.

For watercore, it is a physiological disorder of pear fruit characterized by water-soaked regions and translucent looking in the flesh. When watercore is severe, it is externally visible by the dark skin at the affected area. In mild and moderate cases, the affected areas are around the core and the damage is invisible on the skin. ${ }^{2}$ There are many ways to investigate watercore, such as floatation which is based on the fact that watercore fruits have more specific gravity than nonwatercored fruits. But this method is difficult to operate since the density also depends on temperature of flotation solution. ${ }^{3}$ Pears cultivated by the Royal Project Foundation (RPF) have been detecting this internal defect by randomly cutting the fruits. Since there is no process to determine sugar content, and the cutting method for detecting watercore caused a huge loss and could not guarantee the quality of each pear, a nondestructive evaluation is a desirable way for both producer and customer. X-Ray CT imaging and Magnetic Resonance Imaging (MRI) are nondestructive methods that are used to differentiate normal and core breakdown pears and exhibited good results. ${ }^{4}$ However, both the methods are very complicative and needed high price instruments which are not suitable for farmers and small enterprises.

Near infrared (NIR) spectroscopy is an alternative low cost nondestructive method. This method is fast (one minute or less per sample) with minimum sample preparation demands, noninvasive with high penetration of the radiation beam, suitable for in-line use; nearly universal application (any molecule containing $\mathrm{C}-\mathrm{H}, \mathrm{N}-\mathrm{H}, \mathrm{S}-\mathrm{H}$ or $\mathrm{O}-\mathrm{H}$ bonds). ${ }^{5}$ NIR spectroscopy has been applied for predicting chemical composition and total soluble solids in various fruits such as apples, ${ }^{6}$ oranges, ${ }^{7}$ mangoes. ${ }^{8}$ NIR was also used for detecting internal defect for example, detecting watercore in apples ${ }^{9}$ using reflection mode. The result from that research showed that watercore and normal apples were differentiated with only $4 \%$ of error.

The objectives of this study were to develop a model for predicting sugar content and to develop a discrimination (classification) model for nondestructive detection of watercore in pear.

\section{Materials and Methods}

\subsection{Samples}

A total of 93 samples of Asian pear variety "SH-078" from the Royal Project Foundation (RPF) were kept at $4{ }^{\circ} \mathrm{C}$ during transportation process. The samples were temperature-controlled by putting them on a plastic sheet stretched over the surface of a water bath at $28^{\circ} \mathrm{C}$ for $10 \mathrm{~min}$. Pears at this constant temperature were used for spectral acquisition, analyzing sugar content and assessing watercore.

\subsection{NIR measurement}

\subsubsection{Sugar content detection}

Spectrum of each fruit was measured by a handheld NIR spectrometer (FQA-NIRGUN, Fantec, Japan), operating in the short wavelength region (700$1100 \mathrm{~nm}$ ) with spectral resolution $2 \mathrm{~nm}$ in the reflection mode. Two spectra were recorded from two positions of each fruit, one was at the perpendicular direction against the core of the pear and the other was at the opposite site of the previous position (Fig. 1). In this study, polytetrafluoroethylene

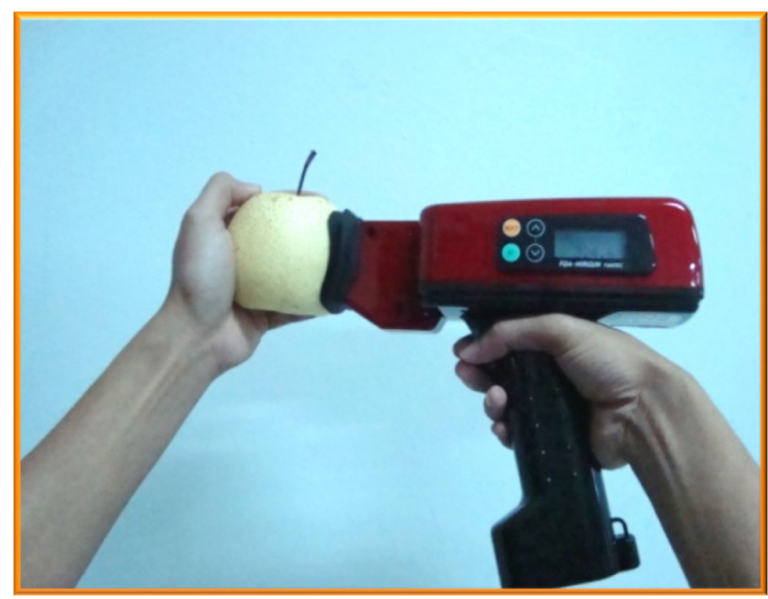

Fig. 1. The measuring of NIR spectrum on a pear in reflectance mode using FQA-NIRGUN (Fantec, Japan). 
(PTFE; the most well-known brand name is Teflon) was used as a reference material because it is nonreactive, resistant to high temperature, and it does not absorb light in NIR region. One spectrum was measured per sample and a reference measurement was performed after five spectra.

\subsubsection{Watercore detection}

NIR measurement was performed by a PureSpect NIR instrument (Saika TIF, Japan) over the short wavelength range $(700-850 \mathrm{~nm})$ with spectral resolution $1 \mathrm{~nm}$ in the transmission mode. NIR spectra were measured at the perpendicular direction against the core of the pear (Fig. 2). One spectrum was measured per sample and a reference measurement was performed after five spectra.

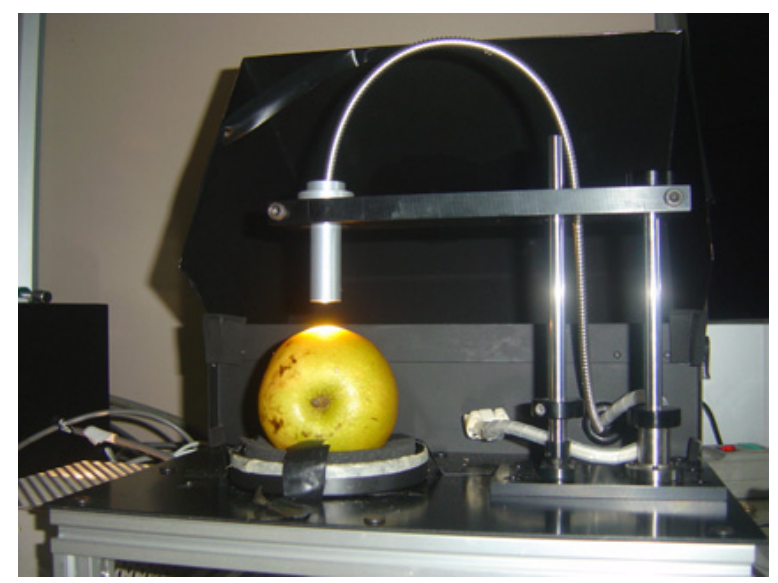

Fig. 2. The measuring position of pear on a PureSpect NIR instrument (Saika TIF, Japan).

\subsection{Reference method}

\subsubsection{Sugar content analysis}

Flesh at positions of the spectra acquisition was cut into $1 \mathrm{~cm}$ thickness and juice was extracted. Sugar content was determined using Digital Refractometer (Atago PR-32 $\alpha$, Japan). The results were shown in a term of degree Brix $\left({ }^{\circ} \mathrm{Bx}\right)$ which approximate the percentage of total dissolved solid in the solution $(\% \mathrm{w} / \mathrm{w})$.

\subsubsection{Watercore assessment}

After determining the absorption, each pear was sliced in to $1 \mathrm{~cm}$ thickness through the equator and was photographed with a digital camera (Olympus, Japan). A grid was placed over the picture, and the number of intercepts (crosses on the grid) in the water-soaked region was counted and then transformed to be area $\left(\mathrm{cm}^{2}\right)$. The percentage of watercore affected area was calculated across the entire fruit cross section. ${ }^{10}$ Fruits with water-soaked tissue less than $5 \%$ of cross-sectional area were accepted (Fig. 3), while fruits with more than $5 \%$ watersoaked tissue would be rejected.

\subsection{Development of equation for predicting sugar content}

Spectra pretreated by first derivative (segment 8 points and smooth 12 points) were correlated with sugar content obtained from laboratory. Prediction equation was performed by multiple linear regressions using CA Maker program (Shizuoka Shibuya Seiki, Hamamatsu, Japan). Predictive variables in the equations were chosen by the stepwise method.

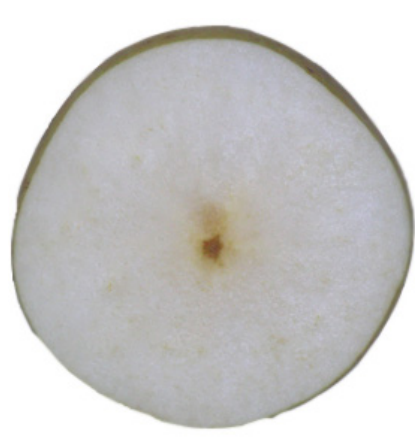

(a)

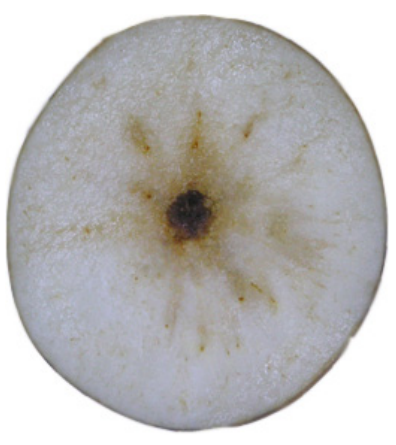

(b)

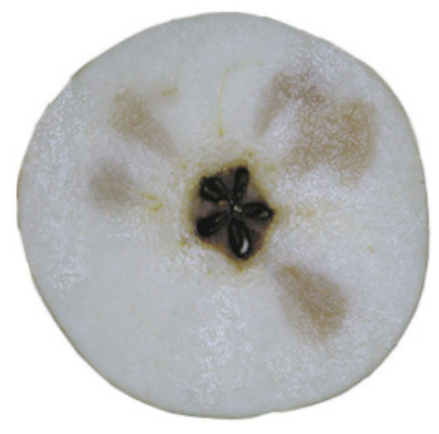

(c)

Fig. 3. Normal (a), less than $5 \%$ watercore-affected (b), and rejected pear (c). 


\subsection{Discrimination model for watercore damage}

A nondestructive discrimination model for predicting watercore damage was developed using the relationship of the internal qualities and near infrared (NIR) absorbance in the short wavelength region $(700-850 \mathrm{~nm})$. Prior to develop the model, the spectra were pretreated with the first derivative (number of left and right side were 5 points). Unscrambler software version 9.8 (Camo, Oslo, Norway) was used to perform PCA and PLSDA which was assigned the dummy variables as 0 for accepted and 1 for rejected pears.

\section{Results and Discussion}

\subsection{Sugar content}

Spectra were pretreated by first derivative (segment 8 points and smooth 12 points) owing to baseline shift appearance. Samples were separated into two sets: calibration set for developing prediction equation containing 60 fruits and validation set for testing equation accuracy containing 33 fruits. Results were shown by scatter plots in Figs. 4 and 5 for calibration and validation set, respectively. These scatter plots showed accuracy of prediction values with Correlation coefficient $(R)=0.91$, Standard Error of Calibration $(\mathrm{SEC})=0.46^{\circ} \mathrm{Bx}$, Standard Error of Prediction $(\mathrm{SEP})=0.58^{\circ} \mathrm{Bx}$, and Bias $=0.11$. The result from paired $t$-test showed that sugar content predicted by NIR was not significantly different from the value analyzed by refractometer at $95 \%$ confidence. The equation

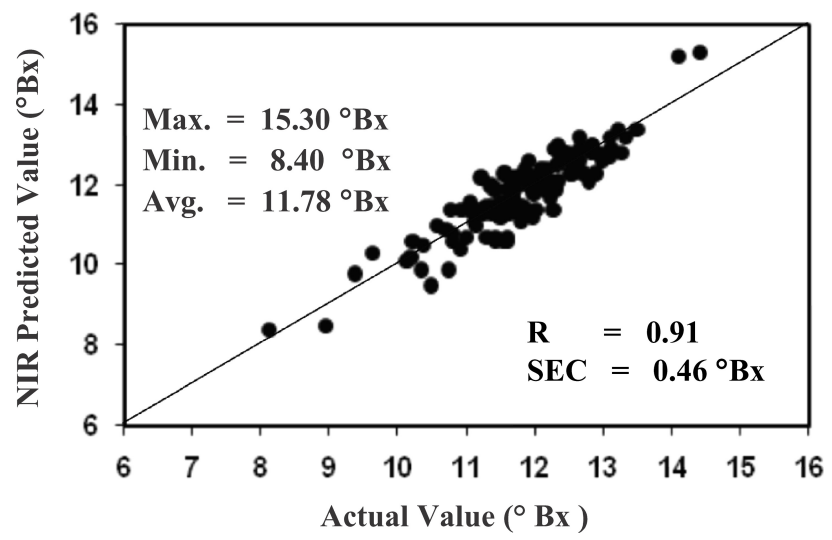

Fig. 4. Scatter plots of predicted and actual values of sugar content in the calibration set.

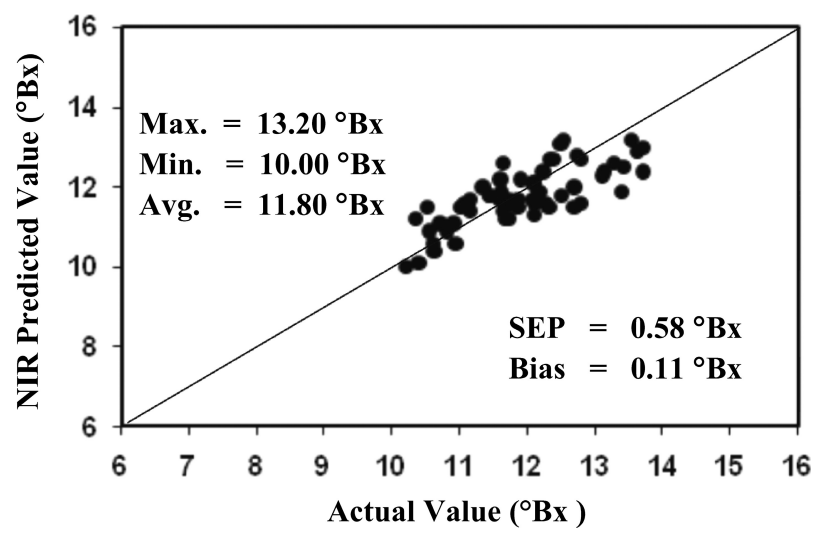

Fig. 5. Scatter plots of predicted and actual values of sugar content in the validation set.

developed for predicting sugar content was shown by Eq. (1).

$$
\begin{aligned}
{ }^{\circ} \mathrm{Bx}= & 9.9945-583.1385 \mathrm{~A}_{766}+576.6359 A_{782} \\
& +794.2063 \mathrm{~A}_{852}-1607.0310 \mathrm{~A}_{886} \\
& +786.0243 \mathrm{~A}_{914}-215.1661 \mathrm{~A}_{936}
\end{aligned}
$$

where $\mathrm{A}_{x}$ is the first derivative of an absorbance at the wavelength of $x \mathrm{~nm}$.

From this equation, all predictive variables are necessary to predict sugar content in pear accurately and the most influential wavelength for predicting sugar content is at $914 \mathrm{~nm}$. This wavelength is related to the absorption of fructose which is the most sugar found in pear. Figure 6 shows the second derivative spectra of fructose absorbing around $900 \mathrm{~nm}$.

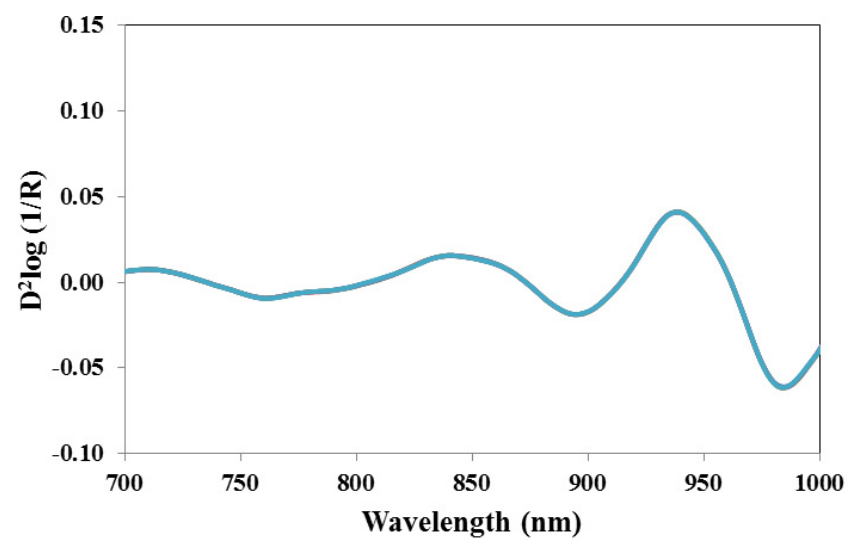

Fig. 6. Second derivative spectrum of sucrose. 


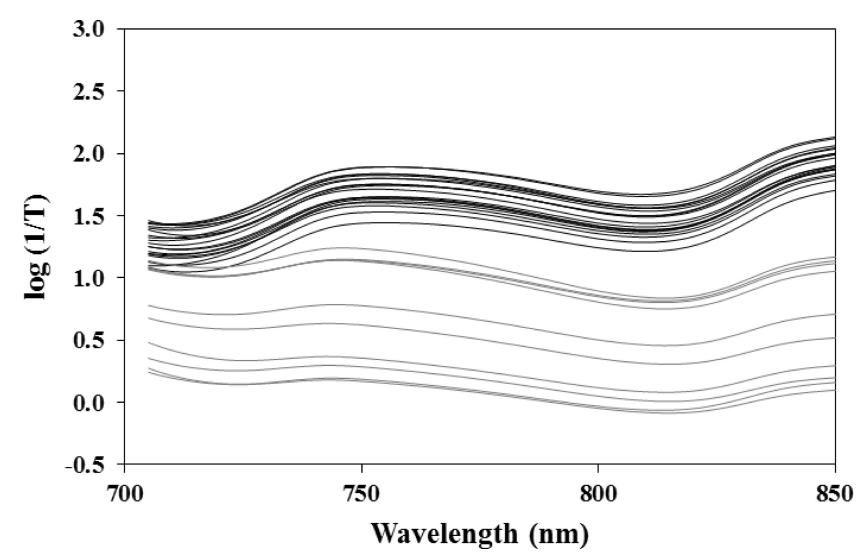

Fig. 7. Original spectra of some samples measured in the wavelength 700-850 nm. Black lines indicated accepted normal pears, and gray lines represented rejected watercore pears.

\subsection{Watercore}

Baseline shifts occurred due to the difference of pear size. Spectra were separated into two groups (Fig. 7). The spectra of the rejected watercore pears were located lower than those of the accepted ones, indicating that the watercore damaged flesh had relatively lower absorption. According to the primary pretreatment, the first derivatives developed using the Savitzky-Golay derivative in the wavelength region of $700-850 \mathrm{~nm}$ was able to reduce baseline shift influence (Fig. 8).

\subsubsection{Discrimination model}

According to the PLSDA result (Fig. 9), the predicted value at 0.50 was used as a criterion because at this point the model presented the most correct

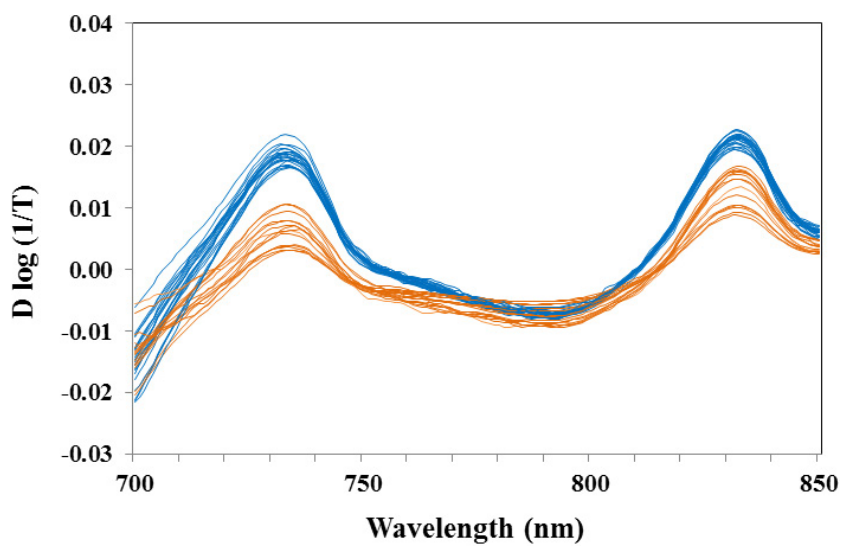

Fig. 8. Spectra of some samples after first derivative pretreatment measured in the wavelength 700-850 nm. Black lines indicated accepted normal pears, and gray lines represented rejected watercore pears.

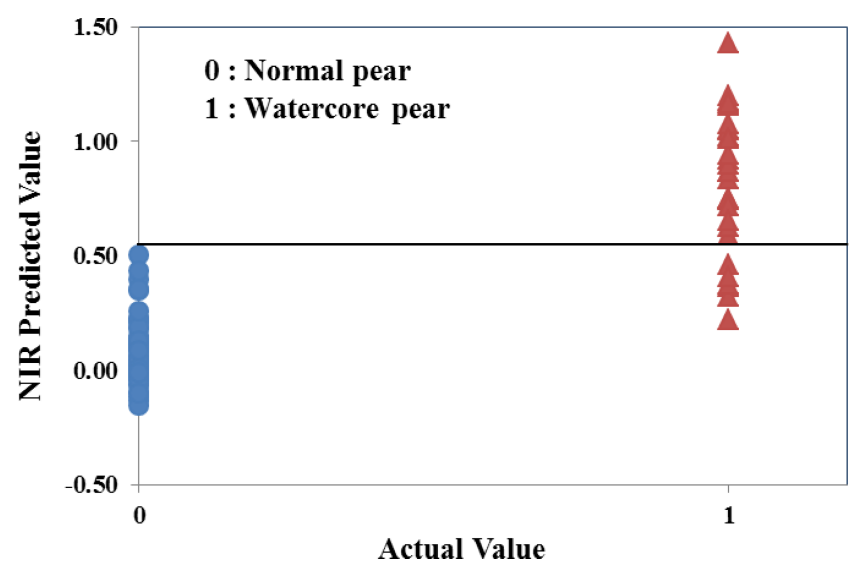

Fig. 9. The PLSDA plot of NIR predicted value and actual value for discriminating watercore-damaged pears $(0=$ accepted, $1=$ rejected $)$.

result compared with the actual value. Fruits that showed predicted values not exceed 0.50 would be accepted while fruits with more than 0.50 predicted values would be rejected. This model predicted $100 \%$ normal pears and $79 \%$ watercored pears correctly. It meant that $21 \%$ of watercore pears would be accepted as normal ones according to NIR prediction. The PLSDA regression coefficients plots which are the regression coefficients plotted against wavelength is shown in Fig. 10. The peaks in the plot show the major wavelengths needed to predict pear quality groups. In this figure, large negative peaks were observed at 735 and $830 \mathrm{~nm}$. From the PCA score plot (Fig. 11), the most important PC factor influencing the model was PC1 which scored very positively for watercore-damaged pears. The scores were separated into two boundaries, one predicted rejected pears with $100 \%$ classification

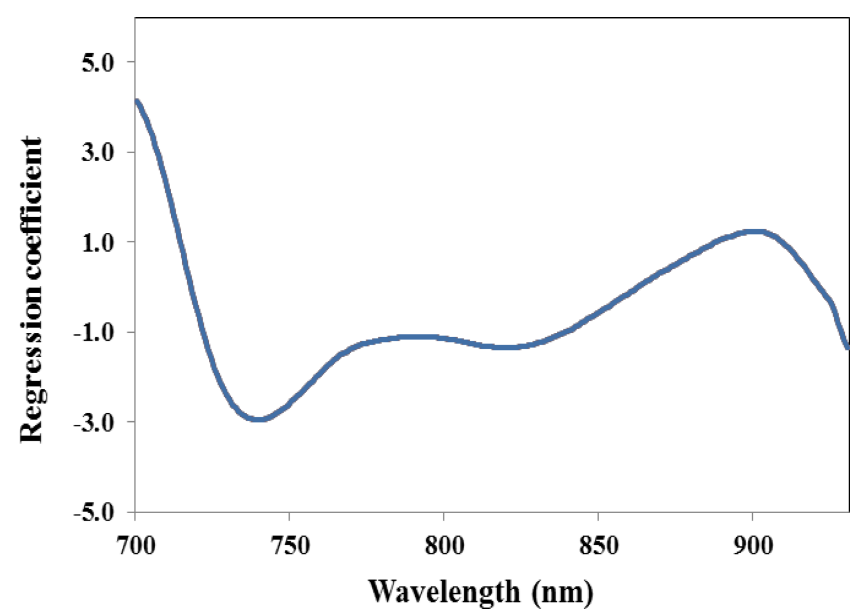

Fig. 10. Regression coefficient plots for PSLDA model. 


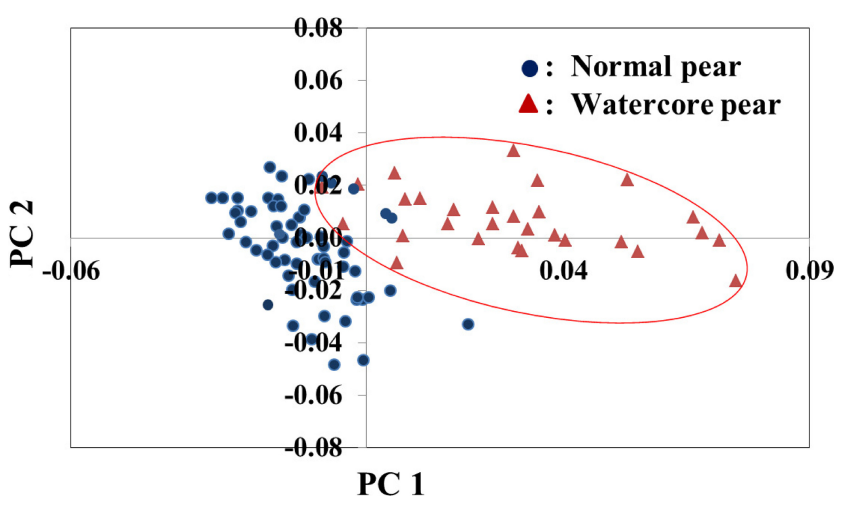

Fig. 11. Score plots PC1 and PC2 from discrimination model of watercore by $\mathrm{PCA}(\bullet=$ accepted pear, $\boldsymbol{\Lambda}=$ rejected pear $)$.

accuracy, and the other was accepted pears with $92 \%$ accuracy. From PCA results, only $8 \%$ of normal pears were predicted by NIR as rejected ones. It was good for customers because there will be no watercore fruits mixed with normal fruits, and since the accuracy of the PCA model was greater than the PLSDA one, it was suitable for commercial purposes to identify watercore damaged pears correctly. The PC1 loading plot shown in Fig. 12 revealed that the absorption at $732 \mathrm{~nm}$ was the most significant factor to distinguish between two groups, followedby the absorption at $830 \mathrm{~nm}$. These corresponded to the wavelengths used in PLSDA model shown in Fig. 10 and they were obviously seen in the first derivative spectra where the absorbance of accepted pears at 732 and $830 \mathrm{~nm}$ was greater than rejected pears (Fig. 8). The reason was that the watercore-damaged pears are relatively translucent, and allow light at $830 \mathrm{~nm}$ to be transmitted to a greater degree than normal pears, which

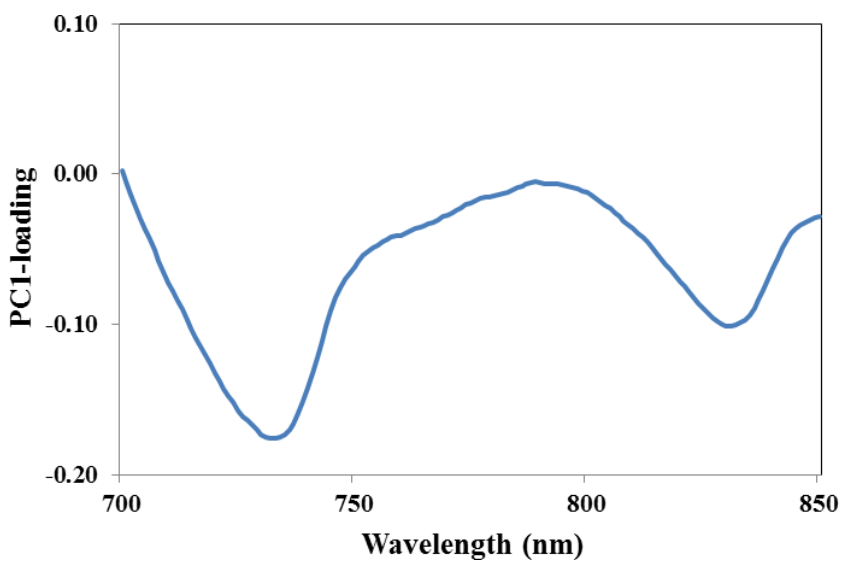

Fig. 12. Loading plot of principle component (PC1). are relatively opaque. Moreover, the spaces between cells in watercore affected fruit were filled with fluid instead of air therefore, the constituent concentration was lower than normal fruit and consequently lowered the absorption.

\section{Conclusion}

NIR technology at short wavelength region exhibited sufficient accuracy for predicting sugar content and detecting watercore damage in Asian pears for commercial purpose. The PCA model was able to classify internal quality with $92 \%$ correctly of the time.

\section{Acknowledgment}

The research fund was supported by IRPUS (The Thailand Research Fund) and Center of Excellence Project from Research and development Institute at Kamphaengsaen. The authors appreciated the Royal Project Foundation for pear samples and FQA-NIRGUN, and Kasetsart Agricultural and Agro-Industrial Product Improvement Institute for providing us PureSpect NIR spectrometer as well as Miss Khemmanut Pookpul and Mr. Wiraphong Choonui for great contribution on measuring spectra and developing calibration models.

\section{References}

1. Ministry of Agriculture and Cooperatives, Pear, Available at http://www.moac.go.th/builder/ bhad/sali.php.

2. N. Jarassamrit, Temperate Fruits, Ruakeaw Publishing, Thailand (1994).

3. WSU Tree Fruit Research \& Extension Center, College of Agricultural, Human, and Natural Resource Sciences, Washington, USA, Understanding watercore, Available at http://postharvest.tfrec.wsu.edu/pages/N3I4A.

4. J. Lammertyn, T. Dresselaers, P. Van Hecke, P. Jancsók, M. Wevers, B. M. Nicolaï, "MRI and X-ray CT study of spatial distribution of core breakdown in 'Conference' pears," J. Magn. Reson. Imaging 21, 805-815 (2003).

5. C. Pasquini, "Near infrared spectroscopy: Fundamentals, practical aspects and analytical applications," J. Bra. Chem. Soc. 14(2), 198-219 (2003).

6. V. A. McGlone, P. J. Martinsen, "Transmission measurements on intact apples moving at high speed," J. Near Infrared Spectrosc. 12, 37-43 (2004). 
7. S. Kawano, T. Fujiwara, M. Iwamoto, "Nondestructive determination of sugar content in Satsuma mandarin using near infrared (NIR) transmittance," J. Japan. Soc. Hort. Sci. 62(2), 465-470 (1993).

8. S. Sarangwong, J. Sornsrivichi, S. Kawano, "Improvement of PLS calibration for Brix value and dry matter of mango using information from MLR calibration," J. Near Infrared Spectrosc. 9, 287-295 (2001).
9. S. Tsuchikawa, S. Kumada, K. Inoue, "Application of time-of-flight near-infrared spectroscopy for detecting water core in apples," J. Am. Soc. Hort. Sci. 127(2), 303-308 (2002).

10. F. Roger Harker et al., "Maturity and regional influences on watercore development and its postharvest disappearance in 'fuji' apples," J. Am. Soc. Hort. Sci. 124(2), 166-172 (1999). 